\title{
ASSESSMENT OF TEST METHODS FOR FRECKLE FORMATION IN Ni-BASE SUPERALLOY INGOTS
}

\author{
Koji Kajikawa, Masaru Tanaka, Shigeru Suzuki, and Hitohisa Yamada \\ The Japan Steel Works, Ltd.; 4 Chatsu-machi, Muroran, Hokkaido, 051-8505, Japan \\ Keywords: Freckle, Channel segregation, Vertical directional solidification, Horizontal \\ directional solidification, Liquid density, A-USC candidate material
}

\begin{abstract}
Ni-base superalloys are well-known as freckle prone materials. Various researchers have reported on several types of test methods for investigating the freckle formation conditions in $\mathrm{Ni}$ base superalloy ingots. Although varieties of test methods have been studied, there seem to be few articles comparing the test methods. In order to reveal the characteristics of the test methods, some of the test methods were compared. This study shows which test method could be more suitable for the freckling condition in a large ingot. Also, the incompleteness of some of the freckle formation theories is discussed. Using a selected test method, the candidate Ni-base superalloys for an advanced ultra-supercritical (A-USC) steam turbine that would be operated in $700-760^{\circ} \mathrm{C}$ steam conditions were tested. The experiment revealed the freckling tendency of AUSC candidate alloys.
\end{abstract}

\section{Introduction}

The world is facing climate change caused by emissions of carbon dioxide $\left(\mathrm{CO}_{2}\right)$ and other greenhouse gases from human activities. Reducing greenhouse gas emissions requires new technologies. Coal is the primary fuel for the generation of electricity in the U.S., Japan, and many other countries ${ }^{1-3)}$. Coal fired power plants are one of the main sources of $\mathrm{CO}_{2}$ emissions. In order to reduce $\mathrm{CO}_{2}$ emissions from coal-fired power plants, the development of integrated gasification combined cycle (IGCC) technology and advanced ultra-supercritical (A-USC) steam cycle technology have been underway since the 1990's. In the A-USC system, the operating temperature would be $700-760^{\circ} \mathrm{C}$. It is said that a material usable at such high temperatures could be Ni-base superalloys. Some alloys are selected for the A-USC system for their mechanical properties at high temperatures. However Ni-base superalloys are known to be freckle prone. The size of steam turbine components would be much larger than gas turbine components. The freckling tendencies of the materials must be discussed in order to manufacture large components. Several methods for segregation evaluation were reported such as vertical directional solidification experiments and horizontal directional experiments.

Vertical directional solidification (V-DS) experiments are widely used for Ni-base superalloy segregation tests. This experimental method originally comes from the macrosegregation evaluation method $^{4)}$ for surface freckles on directional solidified turbine blades. Density inversion theory derived from V-DS experiments using $\mathrm{NH}_{4} \mathrm{Cl}$ aqueous solution ${ }^{5)}$ is known as one mechanism of freckle formation. V-DS experiments are relatively easy to perform because of their simple apparatus construction. If the freckle formation condition in large ingots can be estimated using V-DS experiments, the V-DS experiments would be expected to be a useful segregation test method for industries. In order to verify V-DS experiments as an evaluation method for channel segregation in large ingots, V-DS experiments were carried out using several Ni-base superalloys as candidate materials for an A-USC turbine. 
Anther method, a horizontal directional solidification (H-DS) experiment, was also carried out to compare the test results. The H-DS experiment is a proven method and has been used in steel industries ${ }^{6-8)}$.

\section{Experimental methods}

Vertical and horizontal directional solidification experiments were performed in order to compare the validity of both methods.

1) Vertical directional solidification (V-DS) experiment

A $50 \mathrm{~mm}^{\mathrm{ID}}, 63 \mathrm{~mm}^{\mathrm{OD}}, 160 \mathrm{~mm}^{\mathrm{L}}$ alumina crucible was used for the V-DS experiments. The test alloy was melted in a high purity Ar gas atmosphere. Both withdrawing downward (upward growth) and pushing upward (downward growth) experiments were performed to investigate the effect of the growth direction on the macro structure of the ingot. FENIX7009), USC141 ${ }^{10)}$, and LTES700 ${ }^{11)}$ developed for $700^{\circ} \mathrm{C}$ applications by Japanese companies were selected for this experiment. In addition, Alloy706 was chosen because it shows downward type segregation compared to upward type FENIX700 though the chemical composition of the alloy is similar to FENIX700. The nominal chemical compositions of the test alloys are shown in Table 1.

The V-DS apparatus used for this experiment is shown in Figure 1. The master ingots of those alloys were melted using a $20 \mathrm{~kg}$ vacuum induction furnace. The ingots were cut to optimum size for insertion into the alumina crucible. The melt weights of test alloys were approximately $1.5 \mathrm{~kg}$ except Alloy706. Because the test material of Alloy 706 was taken from our stock material, the weights of the Alloy 706 ingots were about $1.0 \mathrm{~kg}$.

This V-DS apparatus is different from an ordinary apparatus. In an ordinary apparatus, induction heating is used and a water-cooled ring is placed under the heating device to obtain a steep temperature gradient at solidification. On the contrary, this apparatus uses resistance heat and the temperature gradient is mild as shown in Figure 2 in order to simulate the cooling conditions in a large ingot. Therefore, the mushy zone in the ingot is wide and the condition would be suitable for segregation formation. This apparatus has another unique feature. The crucible is can be moved upward and downward, i.e., the specimen can be solidified directionally in two ways, from

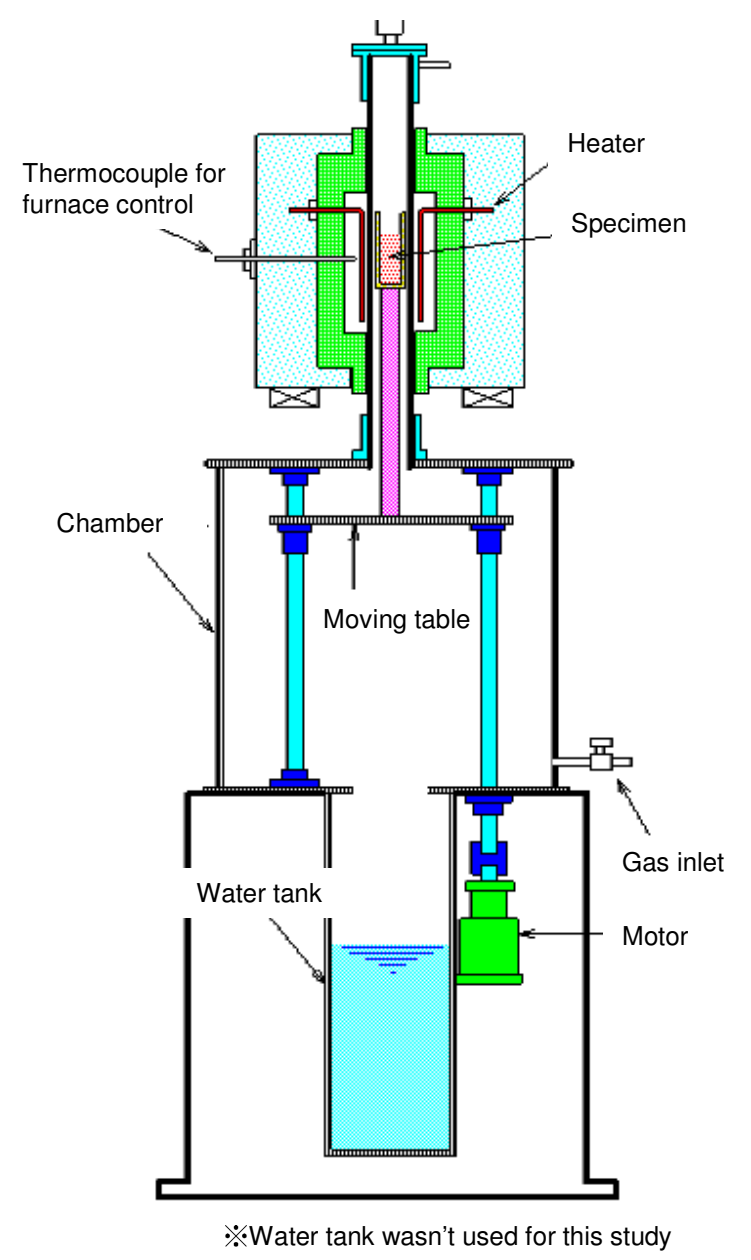

Figure 1 Schematic of V-DS apparatus 
bottom to top and from top to bottom. In this study, the speed of withdrawal downward and pushing upward was $0.5 \mathrm{~mm} / \mathrm{min}$. The vertically solidified ingots were cut longitudinally on the center axis. One side was used for macro structure observation and the other side was cut perpendicular in seven pieces for chemical composition analysis.

\section{2) Horizontal solidification (H-DS) experiments $^{12)}$}

H-DS experiments were also

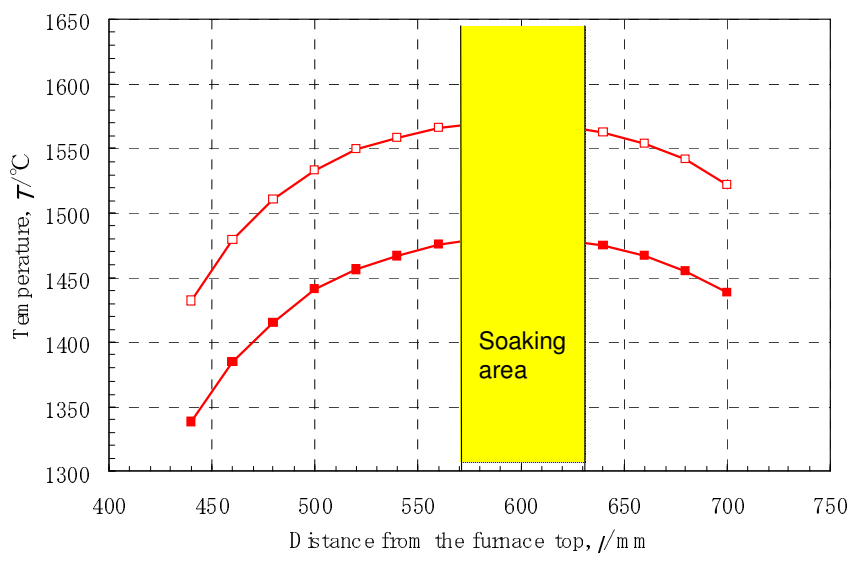

Figure 2 Temperature distribution in the apparatus curried out for various A-USC candidate alloys. The horizontal solidification furnace used for this study is schematically illustrated in Figure 3. In this resistance heat furnace, a rectangular $\mathrm{Al}_{2} \mathrm{O}_{3}$ crucible with an air-cooled chiller was placed. The inner size of the crucible was about $55^{\mathrm{W}} \times 170^{\mathrm{L}} \times 230^{\mathrm{H}} \mathrm{mm}$. Six thermocouples were inserted in the crucible to measure the thermal history of the metal during solidification. The test alloy was melted by an induction melting furnace and poured into the crucible. The pouring temperature was approximately $50-100^{\circ} \mathrm{C}$ higher than the liquidus point of the alloy. Just after pouring, cooling air was blown into the chiller. The molten alloy was horizontally solidified starting from the chiller side. The flow rate of cooling air was optimized in order to acquire freckle plumes in the middle of the ingot. The temperature profile of the liquid alloy was measured until the alloy solidified completely. The horizontally solidified ingot was horizontally cut in crosssections on the plane of the tips of the thermocouples in order to observe the macrostructure.

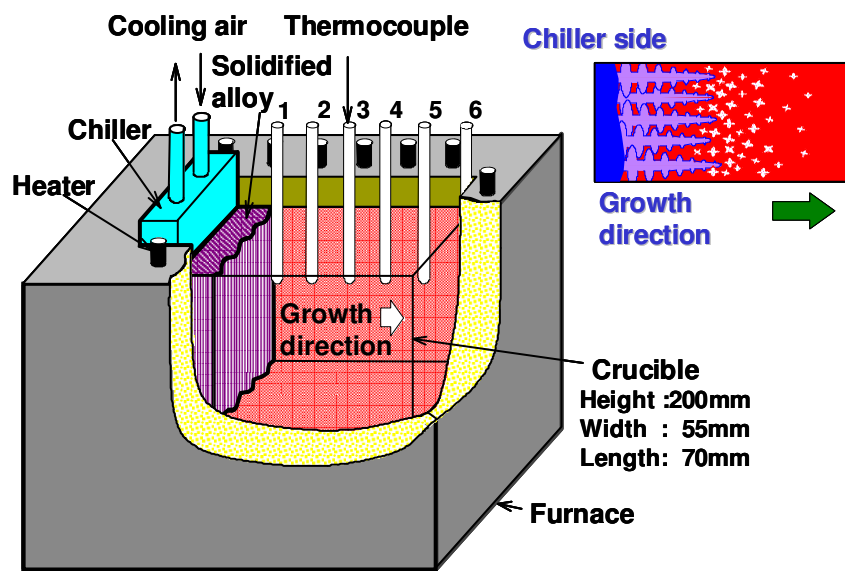

Figure 3 Schematic of the horizontal solidification furnace

\section{Result}

\section{1) Vertical solidification (V-DS) experiment}

Sample macro structures of FENIX700 ingots are shown in Figure 4. The upwardly solidified ingots have large columnar grains. On the other hand, the grains in downwardly solidified ingots are relatively small and the dendrite growth directions seem unstable. Streaklike structures are found in the upwardly solidified USC141 and LTES700 ingots as shown in Figures 5 and 6. These structures are considered to be primary dendrite arms that have a platelike shape. No freckles were found in the interior of the V-DS ingots.

Freckles are observed on the outside surfaces of the V-DS ingots. In particular, USC141 ingots have many freckle streaks that clearly contrast against the matrix. EPMA image analyses on the cross section of the ingots were performed to confirm that the freckle streaks are segregations. As an example of these freckle streaks, the EPMA images of USC141 are shown 

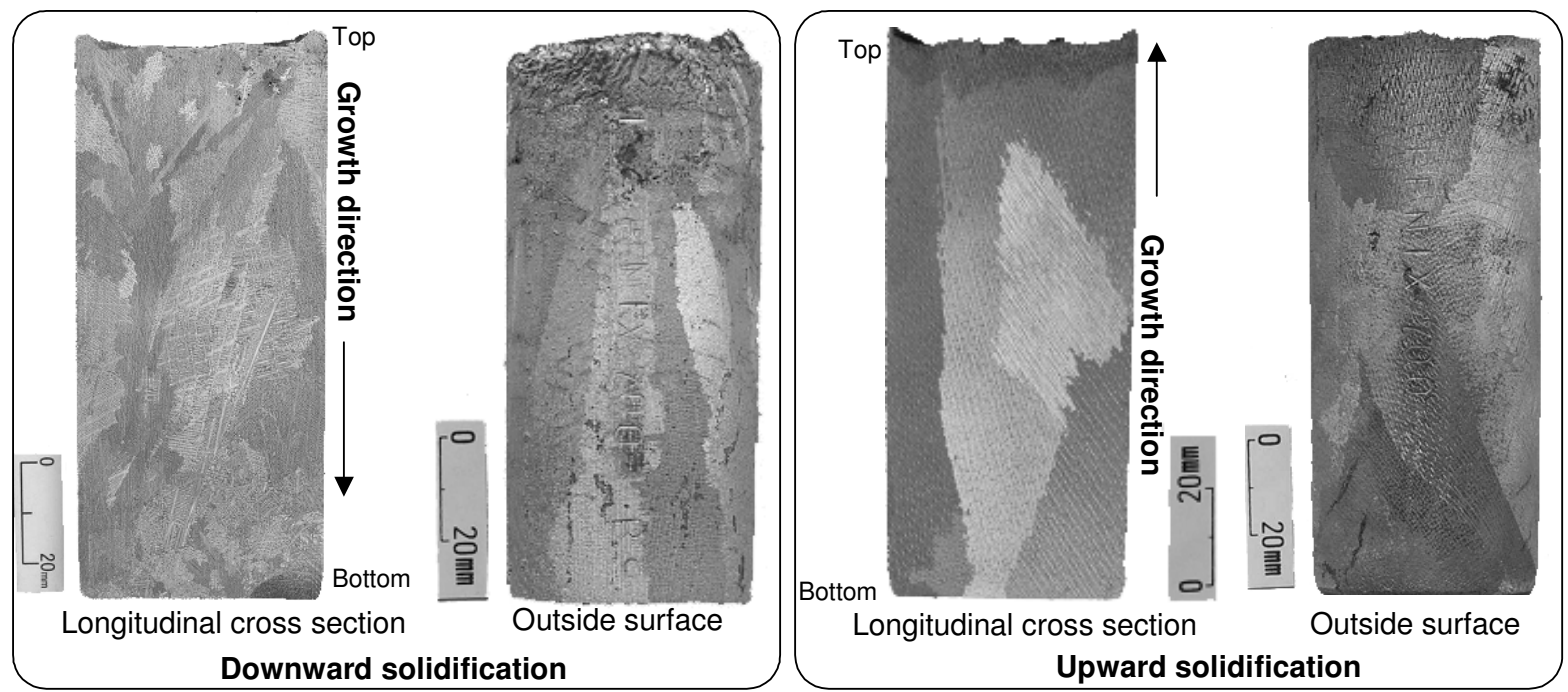

Figure 4 Macrostructure of FENIX700 V-DS ingots
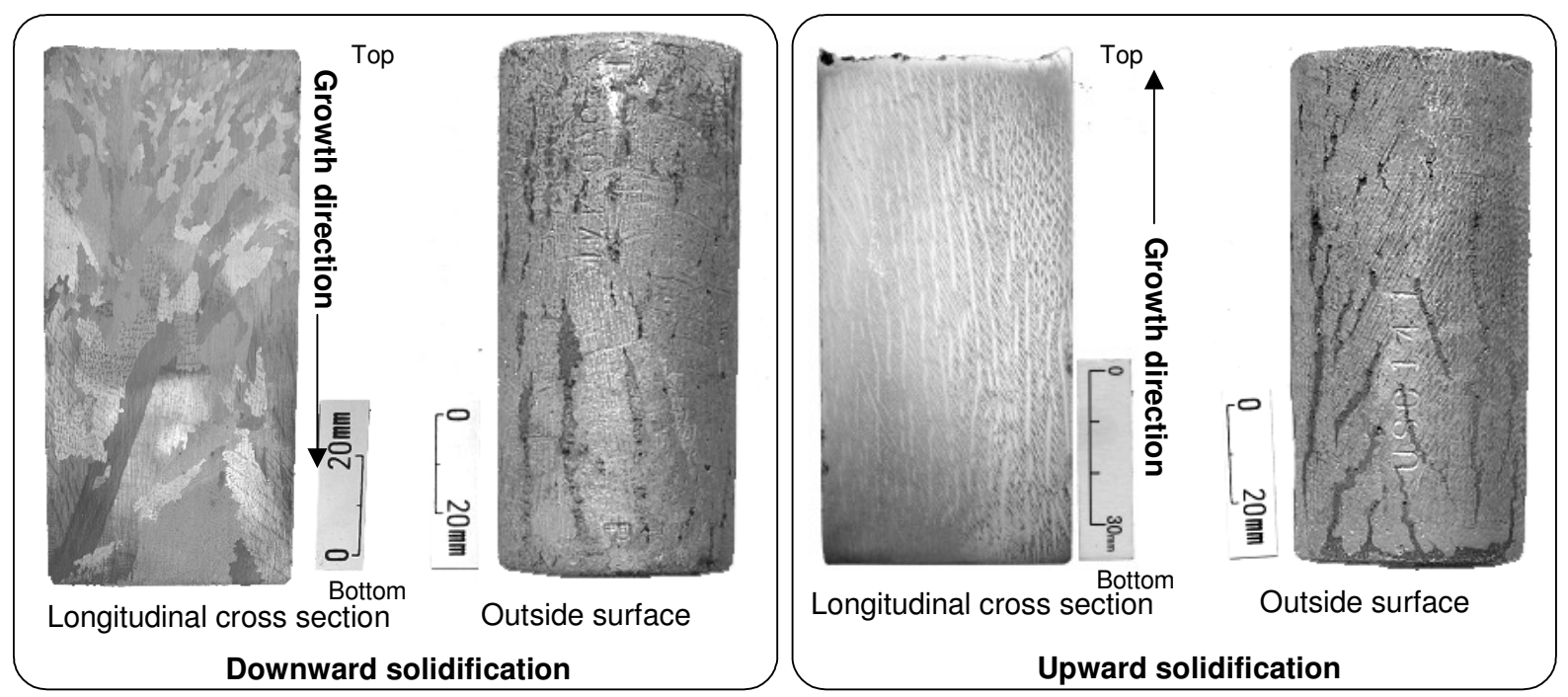

Figure 5 Macrostructure of USC141 V-DS ingots
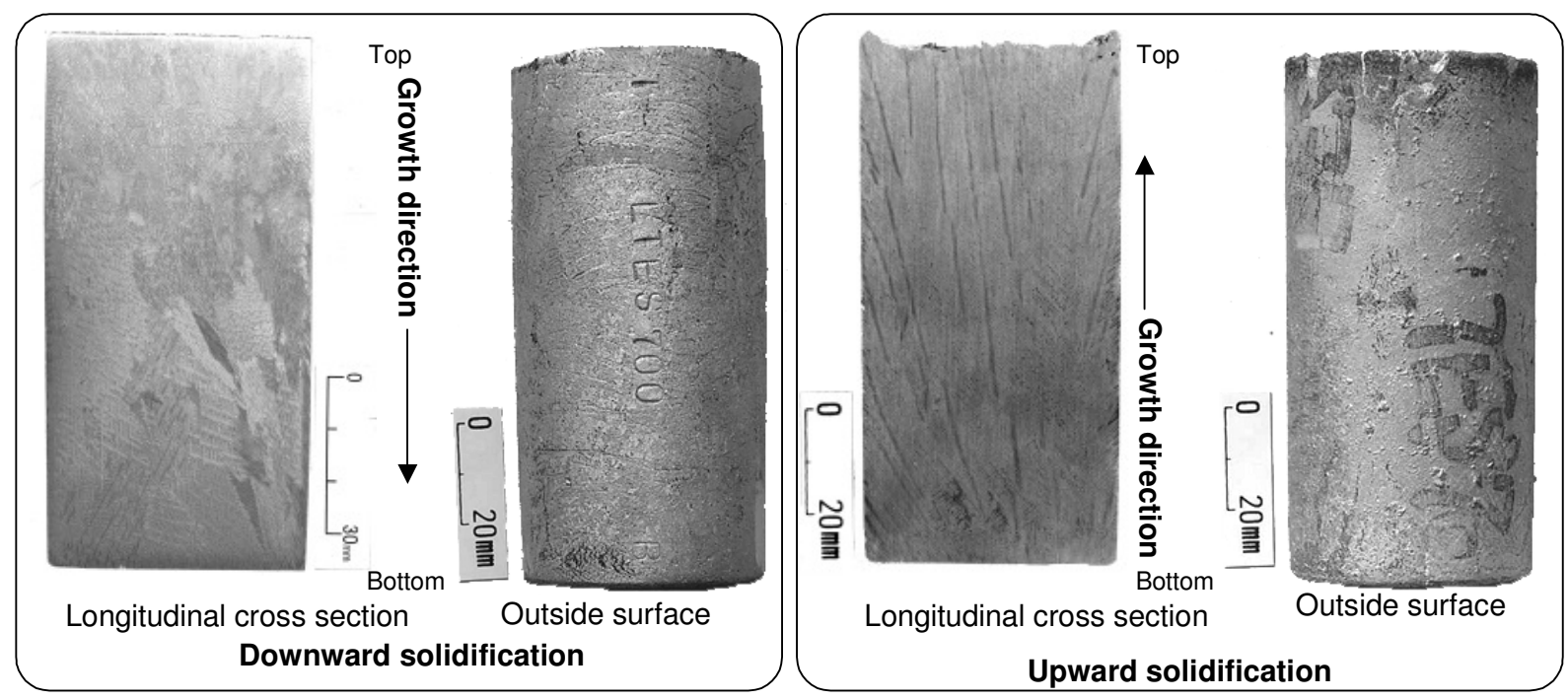

Figure 6 Macrostructure of LTES700 V-DS ingots 
in Figure 7. The freckle portion shows solute concentration. These freckles are segregations. One thing must be noticed about some character-like patterns on the outside surface of the LTES700 upwardly solidified ingot. This pattern is not freckles and is considered to be remnants of white marker pigment $\mathrm{TiO}_{2}$ that were stuck on the inner surface on the crucible. Chemical profiles in the ingots are shown in Figures 8-11. In the figures, the chemical profiles of the ingots are shown as segregation ratios, the ratio between the

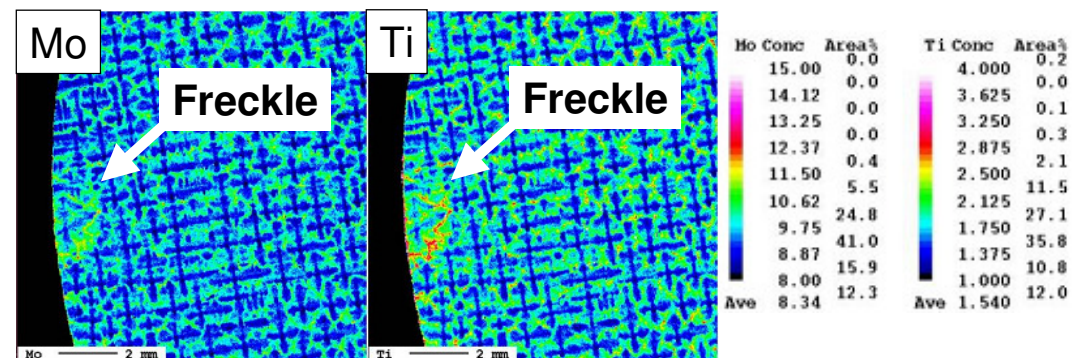

Downwardly solidified USC141 ingot

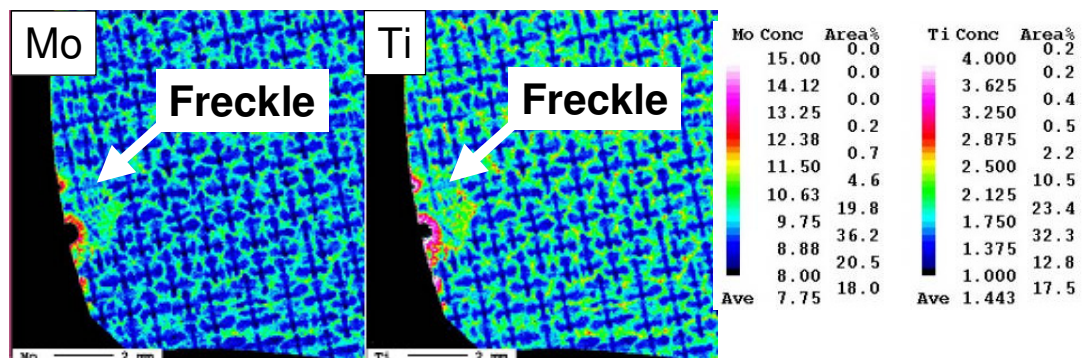

Upwardly solidified USC141 ingot

Figure 7 EPMA images of perpendicular cross-sections of USC141 V-DS ingots

chemical composition of master ingots and the analysis results on each section in the ingots. Some deviations from the average composition are found in Figures 8-11. Those deviations could be due to segregation in the master ingots. Upwardly solidified ingots show that chemical
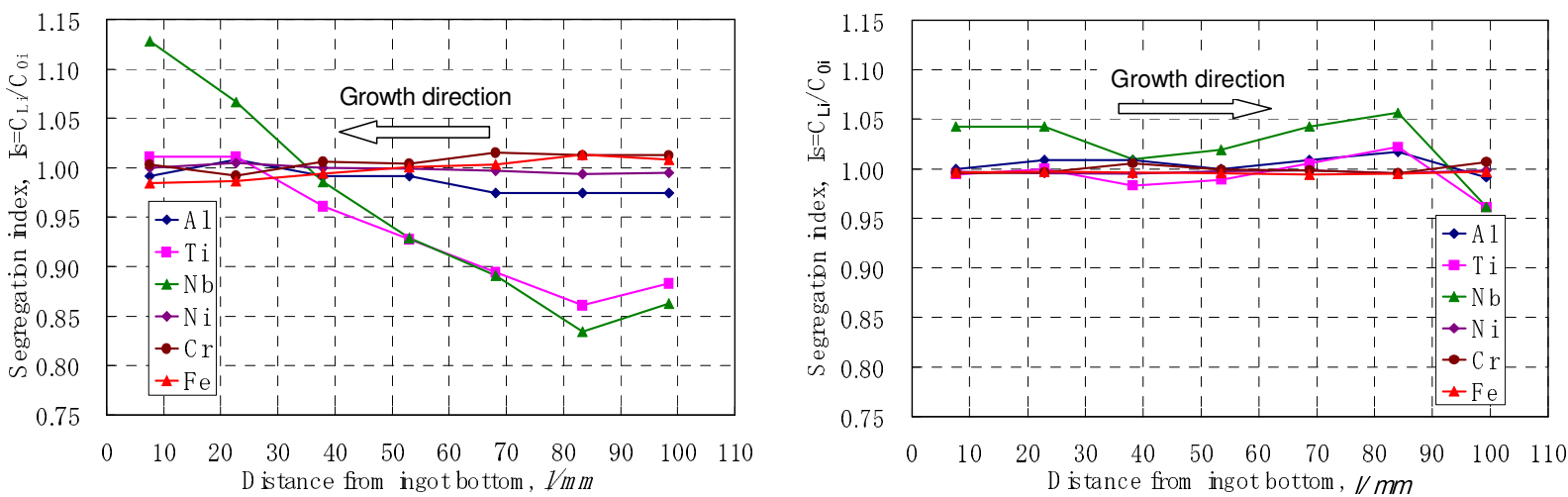

Figure 8 Chemical profiles of FENIX700 V-DS ingots (Left: downward, Right: Upward)
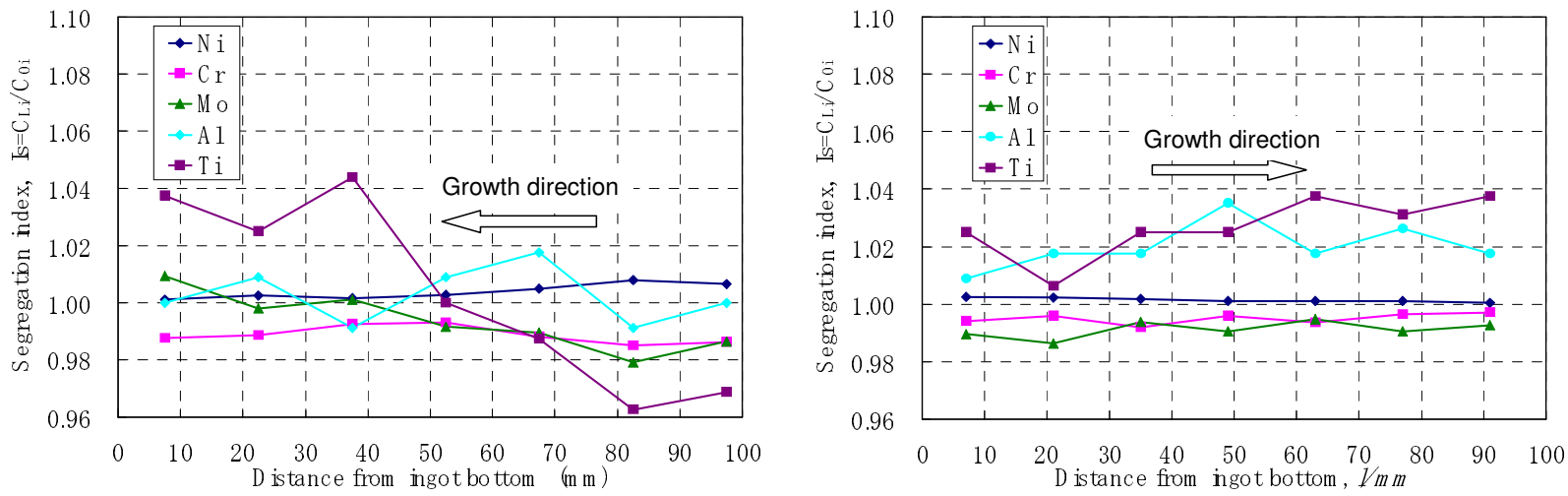

Figure 9 Chemical profiles of USC141 V-DS ingots (Left: downward, Right: Upward) 

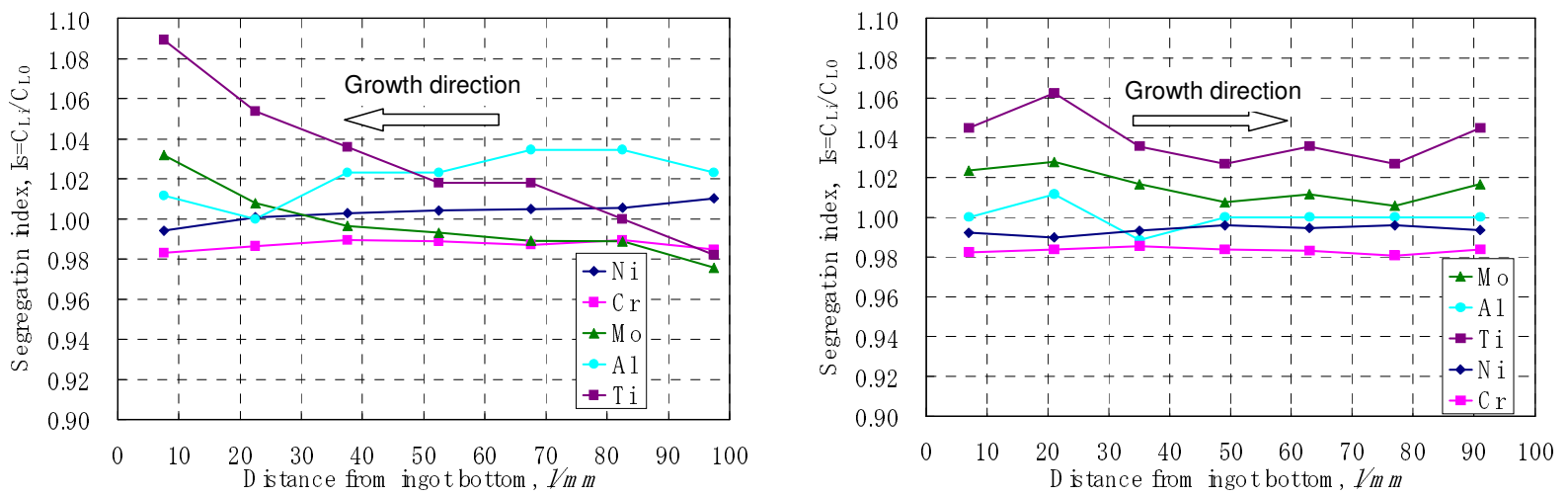

Figure 10 Chemical profiles of LETS700 V-DS ingots (Left: downward, Right: Upward)
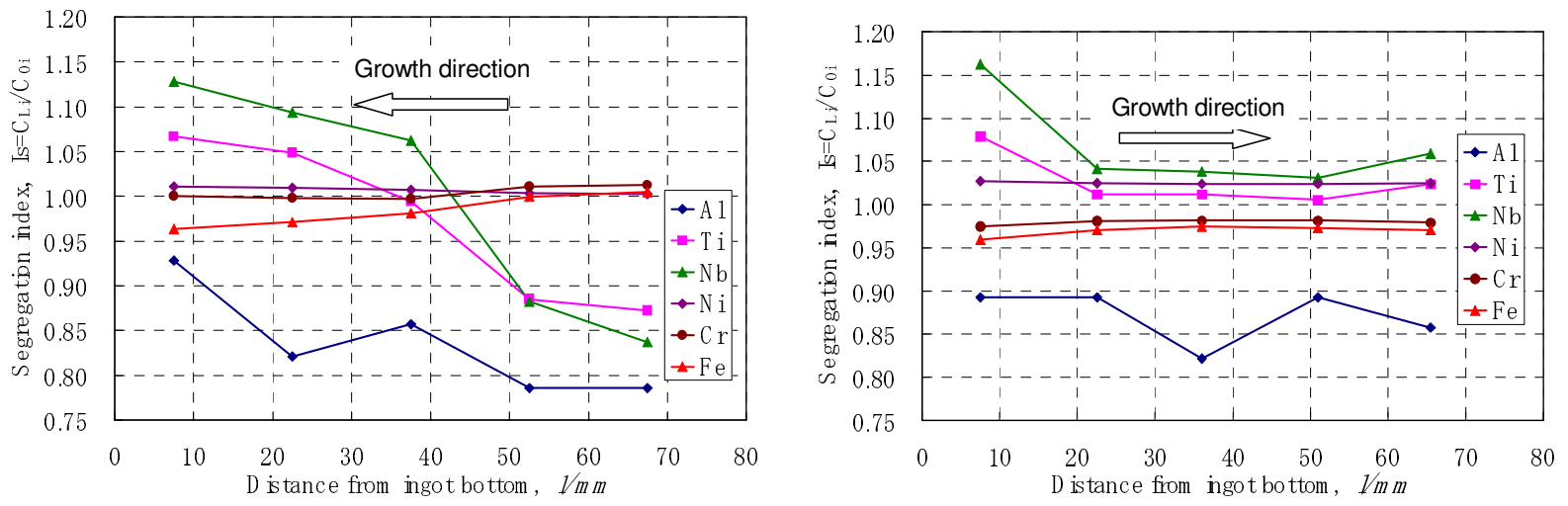

Figure 11 Chemical profiles of Alloy706 V-DS ingots (Left: downward, Right: Upward)

profiles are relatively even. On the contrary, downwardly solidified ingots show that the $\mathrm{Nb}, \mathrm{Ti}$, and Mo contents are changed in the longitudinal direction. Table 2 shows the partition coefficients of test alloys calculated using ThermoCalc $^{\text {TM }}$ 13) with Ni-DATA ${ }^{14)}$. The partitions of $\mathrm{Nb}, \mathrm{Ti}$, and Table 2 Calculated partition coefficients of test alloys

\begin{tabular}{cccccccc}
\hline & $\mathrm{Ni}$ & $\mathrm{Cr}$ & $\mathrm{Mo}$ & $\mathrm{Al}$ & $\mathrm{Ti}$ & $\mathrm{Nb}$ & $\mathrm{Fe}$ \\
\hline FENIX700 & 0.982 & 1.036 & - & 0.797 & 0.326 & 0.160 & 1.092 \\
USC141 & 1.043 & 0.970 & 0.816 & 1.062 & 0.613 & - & - \\
LTES700 & 1.052 & 0.952 & 0.850 & 1.103 & 0.857 & - & - \\
Alloy706 & 0.984 & 1.050 & - & 0.316 & - & 0.157 & 1.094 \\
\hline
\end{tabular}
Mo are larger than other elements. Therefore, the segregation of $\mathrm{Nb}, \mathrm{Ti}$, and $\mathrm{Mo}$ is more severe than the others.

\section{2) Horizontal solidification (H-DS) experiment}

The results of the H-DS experiments are shown in Figure 11. Note that in this experiment, the solidification fronts were not strictly perpendicular to the horizontal line. The fronts form an angle with the horizontal line. Therefore, the columnar grains grew in a slightly upwardly inclined direction. Some of the data have been reported previously ${ }^{15,16)}$. FENIX700 and USC141 showed upward type channel segregation. On the contrary, Alloy706 and LTES700 showed downward type channel segregation. Upward type segregation is the type of macro segregation shown by solute-enriched liquids that are lighter than bulk liquid where segregation channels grow in an upward direction. Downward type segregation is the opposite type and is shown by heavier solute enriched liquid. Both segregations are schematically shown in Figure 12. 

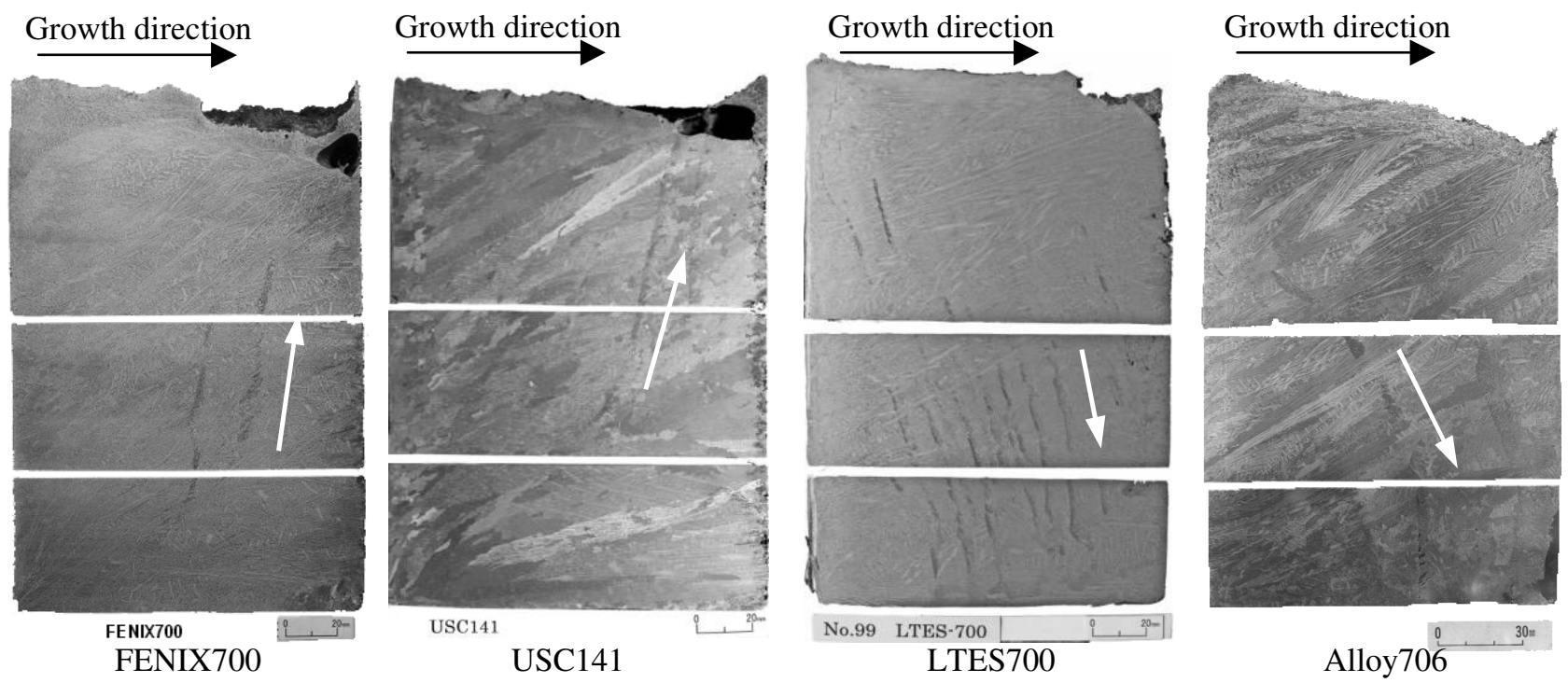

Figure 11 Macro structures of horizontally directional solidified test alloys

\section{Discussion}

It seems that all the test alloys are downward type segregation alloys from the V-DS results because solute concentration in the case of downward solidification is more severe than in the case of upward solidification. However, the H-DS results revealed that FENIX700 and USC141 are upward type segregation alloys. Therefore it is considered that this phenomenon is from a different mechanism.

In the case of downward solidification, because the metal is cooled from the top, the liquid density in the top portion becomes high and a strong downward flow develops. The liquid moving down to the bottom is heated up again and the heated low density liquid rises. The solute enriched liquid ahead of solidification front would be diluted with bulk liquid stirred by strong thermal convection. This kind of phenomenon was observed by Mathiesen and Arnberg ${ }^{17)}$ who performed in-situ observation using an $\mathrm{Al}-\mathrm{Cu}$ alloy and X-ray radiography. In downward solidification, they found that a solute enriched liquid in front of the solidification front was eliminated by convection and the tip of columnar dendrites stuck in the bulk liquid. On the other hand, in the case of upward solidification, because the metal is cooled from the bottom, the density becomes high at the bottom and thermal convection in the liquid is relatively calm. Liquid flow at the solidification front could be small. Therefore, the liquid-solid partition occurs against the solute enriched liquid accumulated at the solidification front. The thermal convection described above is schematically shown in Figure 13. These chemical profile formations could be explained by Figure 14. If strong currents occur at the solidification front, the chemical profile in a directionally solidified ingot becomes like "d" in Figure 14. If the liquid movement ahead of the solidification front is calm, the chemical profile in a directionally solidified ingot becomes like "b" in Figure 14. 
As a freckle test method, the vertical solidification experiment has been carried out for many years. Freckle formation in a vertically solidified ingot is normally explained by the density inversion theory. The density inversion theory is schematically shown in Figure 15 . In the figure, $\rho_{\mathrm{T}}$ is the thermal effect on the liquid density, $\rho_{\mathrm{C}}$ is compositional effect on the density, and $\rho_{\mathrm{T}+\mathrm{C}}$ is the liquid
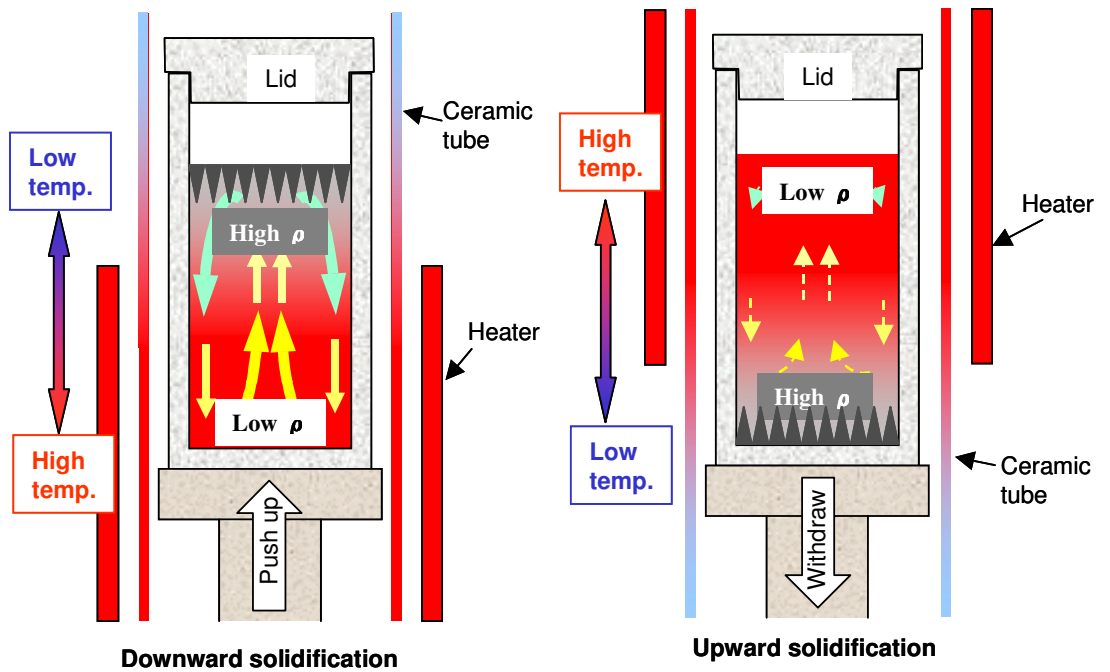

Figure 13. Schematic of convection flow in the V-DS experiment

density profile. In the figure, the heat flow is vertically downward, i.e., from the hot top portion to the cold lower portion. In the case where the rejected solute is lighter than the bulk liquid, the liquid density among the dendrites become lighter than the liquid density ahead of the solidification front. If the density difference effect is larger than the thermal expansion effect on the liquid density, the liquid density profile becomes like $\rho_{\mathrm{T}+\mathrm{C}}$ in Figure 15. This density inversion in the mushy zone causes interdendritic liquid

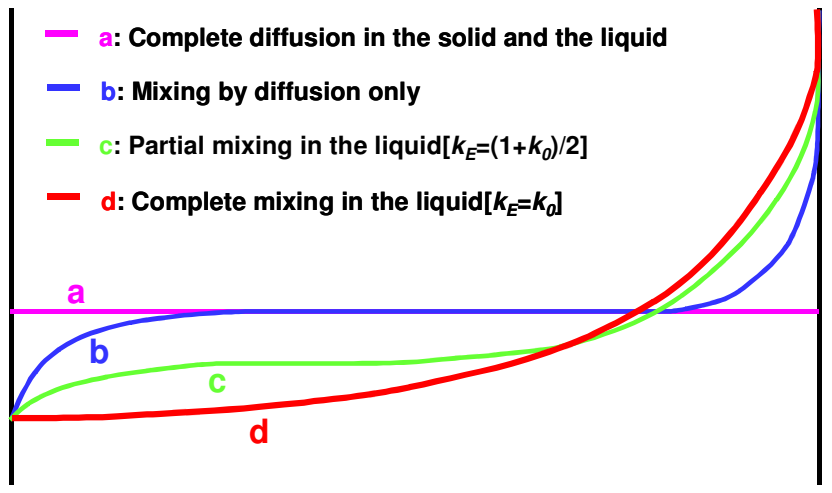

Figure 14 Chemical distributions in an ingot after directional solidification $^{18)}$

flow. The flow makes channels and freckle plumes in the mushy zone. From this density inversion theory, it is impossible to explain freckle formation in downward solidification, such as USC141. The liquid density profile in downward solidification is schematically shown in Figure 16. Unlike upward solidification, the rejected solute is lighter than the bulk liquid, and therefore the rejected solute must stay deep in the seated area of the dendrites and the driving force of

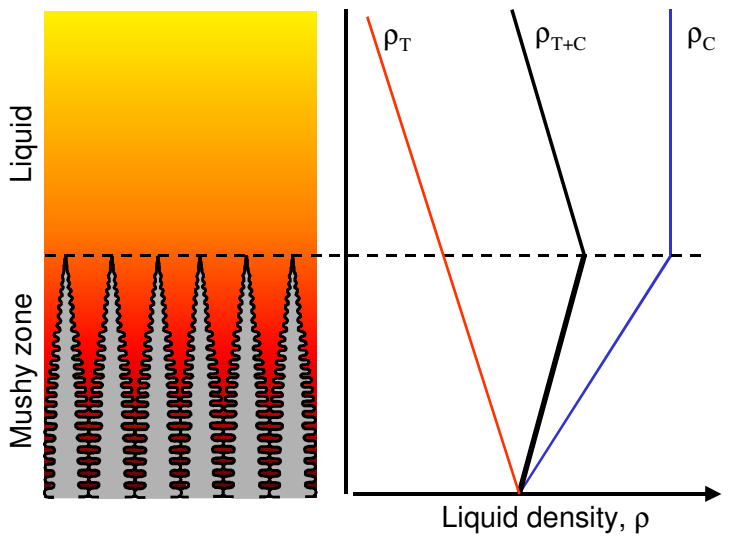

Figure 15 Schematic of the liquid density profile of upward type segregation alloy in upward solidification.

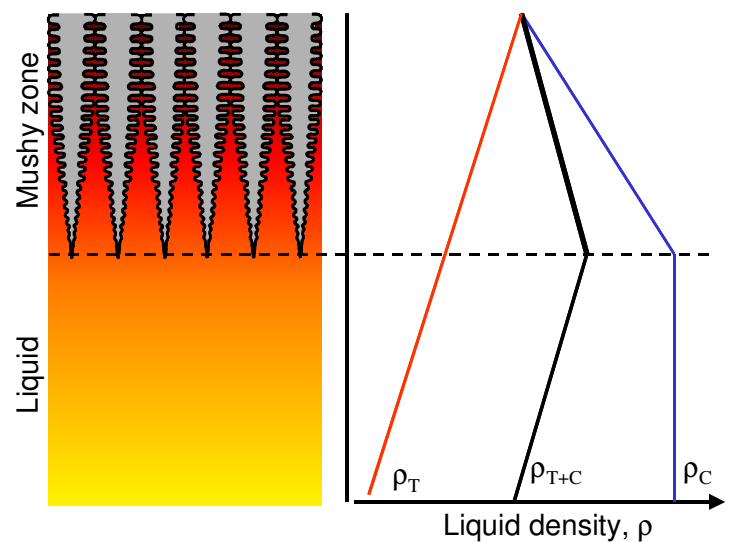

Figure 16. Schematic of the liquid density profile of upward type segregation alloy in downward solidification. 
liquid flow in the dendrites would be quite small. By the same token, the density inversion theory cannot explain downward type freckles in upward solidification. Heavy solute enriched liquid should stay in the dendrites, accordingly little liquid flow should occur in the mushy zone. Streat and Weinberg observed macro segregation in directionally solidified $\mathrm{Pb}-\mathrm{Sn}$ systems ${ }^{19)}$. Sn4 mass $\% \mathrm{~Pb}$ alloy was an example where the interdendritic liquid would be denser than the bulk liquid. They did not find any freckles in the Sn-4mass\% $\mathrm{Pb}$ alloy V-DS ingot.

Copley et al. ${ }^{5}$ showed the effect of growth front curvature on freckle location from their directional solidification experiment using an $\mathrm{NH}_{4} \mathrm{Cl}-\mathrm{H}_{2} \mathrm{O}$ system. If the curvature was concave, freckle plumes appeared at the wall of the mold. Noeppel et al. ${ }^{20)}$ analyzed the effect of electromagnetic forced convection on the segregation during directional solidification. In each case, the freckle channel location coincides with the stagnation point where the flow leaves the columnar front and creates a liquid aspiration effect in the mushy zone. It could be assumed that the growth front curvatures of our ingots are concave to the liquid because freckles appeared on the ingot surface. Generally speaking, freckles are normally located on the exterior surface of a directionally solidified casting ${ }^{4}{ }^{41)}$. In many V-DS experiments, the crucible is withdrawn from the hot zone of the furnace. In this method, the crucible is cooled from outside of the sidewall. Accordingly, the growth front shape would become concave. This shape may cause surface freckles. Freckles appearing on an ingot surface are considered to be different from freckle plumes appearing in the interior of a large ingot.

In the case of the H-DS experiment, stagnation points in the mushy zone would be near the liquid-metal surface and the bottom of the crucible (crucible-metal interface). As shown in Figure 11, the freckle plumes in the H-DS ingots did not originate from the stagnation points but from the middle region of the ingot height. It could be assumed that the freckle formation point does not depend on bulk convection but on local turbulent flow ahead of the growth front. The freckles in the H-DS ingots seem to resemble freckles in large ingots.

Suzuki and Miyamoto ${ }^{12)}$ reported that the critical freckle formation condition could be estimated from the cooling rate $\varepsilon\left({ }^{\circ} \mathrm{C} / \mathrm{s}\right)$ and solidification rate $\mathrm{R}(\mathrm{mm} / \mathrm{s})$, and freckles form at the condition of

$$
\varepsilon \cdot \mathrm{R}^{1.1} \leqq \alpha
$$

The term $\alpha$ here is the alloy inherent value. In other words, $\alpha$ means the freckling critical condition of the alloy $\left(\alpha=\varepsilon \cdot R^{1.1}\right.$ crit). Using the temperature profiles and the thermocouple locations in the H-DS ingots, the cooling rate $\varepsilon\left({ }^{\circ} \mathrm{C} / \mathrm{s}\right)$ and solidification rate $R(\mathrm{~mm} / \mathrm{s})$ can be determined. Figure 17 shows $\varepsilon \cdot R^{1.1}$ crit values of Ni-base superalloys derived from these horizontal solidification experiments. In this figure, smaller values of $\varepsilon \cdot R^{1.1}$ crit means less freckle prone.

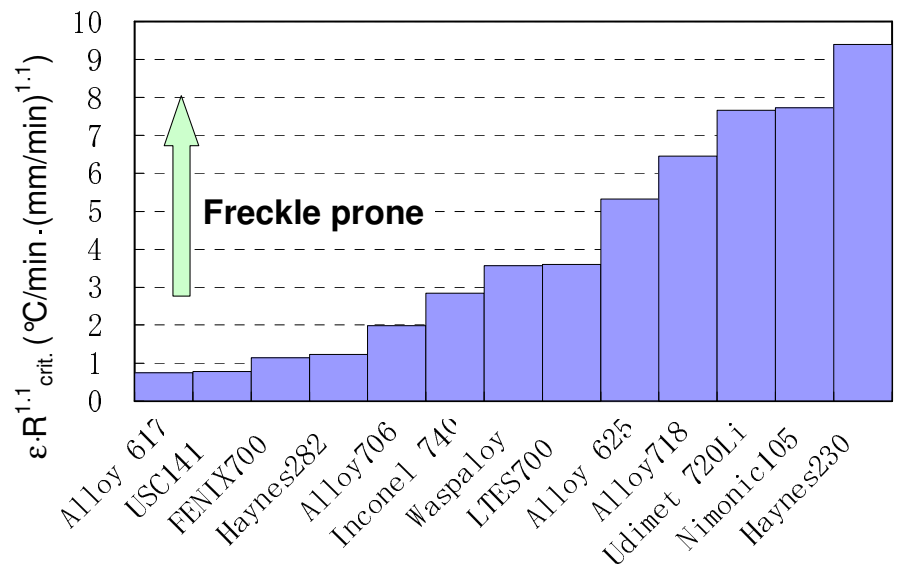

Figure 17 Freckling tendencies of Ni-base superalloys

The density of the liquid alloy can be calculated from the equation shown below because the summation of molar volumes of the elements in the liquid metal could give a good estimate ${ }^{22)}$.

$$
\rho=\sum X_{i} M_{i} / \sum X_{i} V_{i},
$$


where $X_{i}$ is the molar fraction of element $i, M_{i}$ is the molar weight of element $i$, and $V_{i}$ is the molar volume of element $i$. Figure 18 shows the relationship between the calculated liquid densities using the latest data of liquid metal densities ${ }^{23-25)}$. Thermo-Calc ${ }^{\mathrm{TM}}$ with Ni-data was used for this calculation. Although negative values cannot be obtained from the $\varepsilon$. $\mathrm{R}^{1.1}$ equation, in Figure 18, downward type freckles are plotted as negative values in order to distinguish them from upward type freckles. This diagram implies that channel segregation could be estimated from a liquid density difference calculation.

In the V-DS experiments, USC141 seems to be the most freckle prone alloy and the alloy showed a lot of dark streaks on the surface of

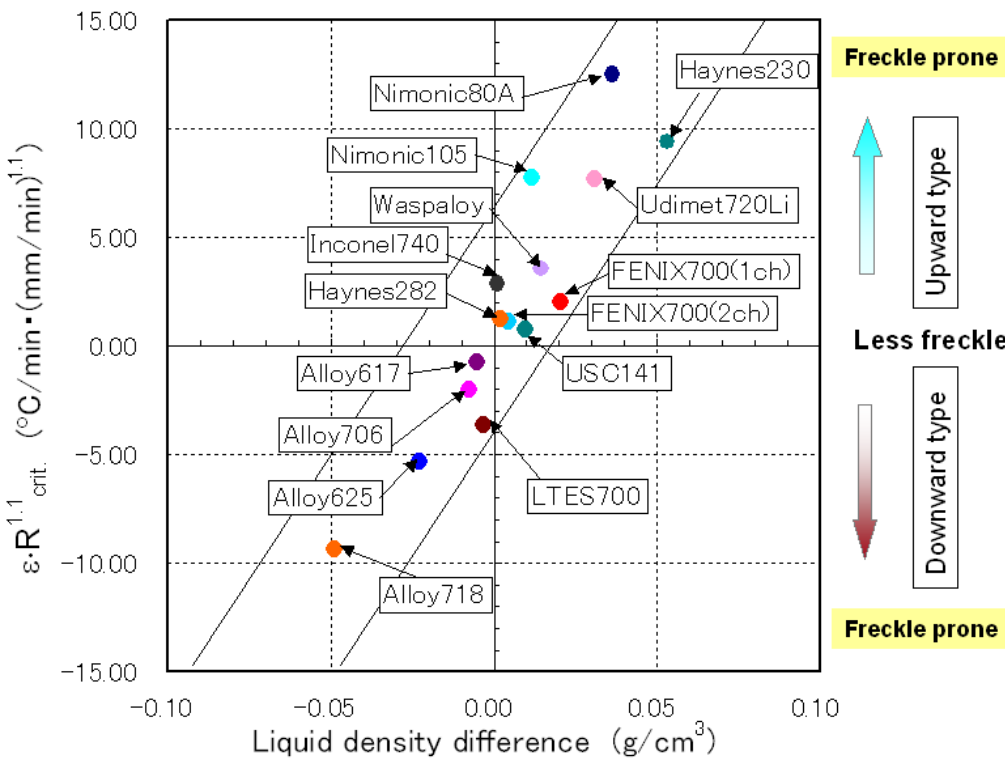

Figure 18 Relation between liquid density differences and freckling conditions

the ingot. However, from the H-DS results, USC141 was found to be one of the least freckle prone alloys.

Alloy706 is similar in composition to the upward type segregation alloy FENIX700 but it shows downward type segregation. The comparison between the chemical profiles in V-DS ingots of both alloys is shown in Figure 19. The height of Alloy 706 is about $70 \mathrm{~mm}$ and is shorter than that of FENIX700 as described previously. Upward type segregation and downward type segregation could be clearly distinguished using the H-DS experiment. Even though the growth direction is changed to emphasize the liquid density difference effect, V-DS experiments could not show the effect of density difference. From the points described above, the V-DS experiment could not explain the freckling tendency of the alloy in large ingots.
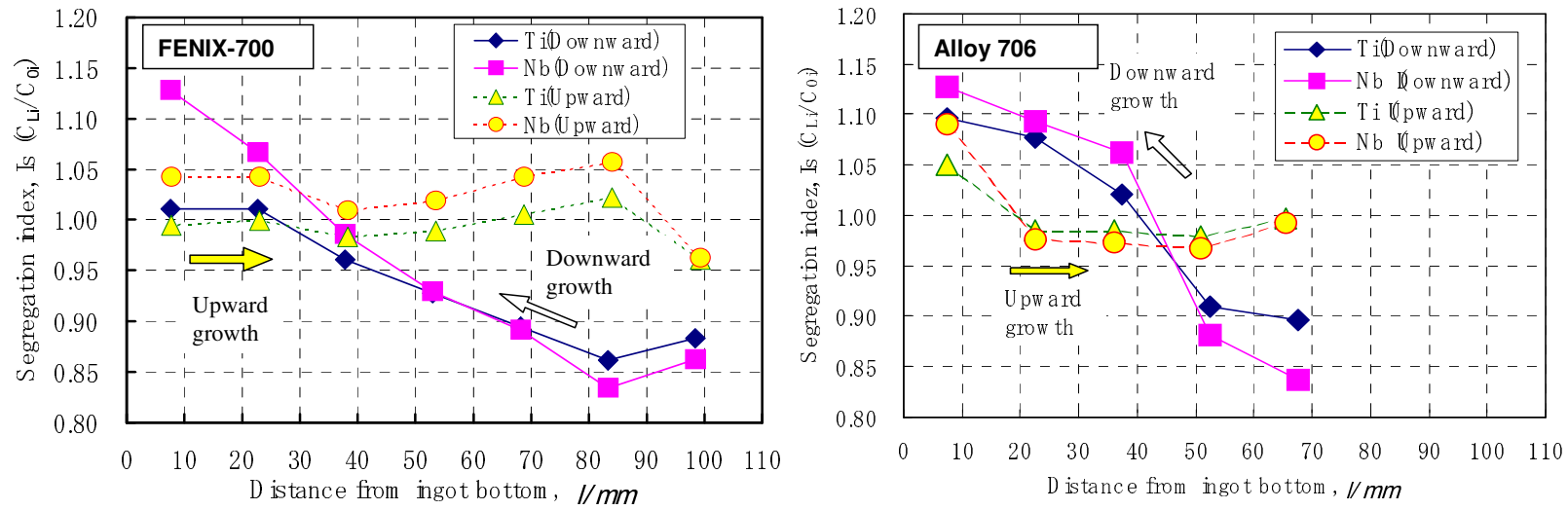

Figure 19 Comparison of chemical profiles between FENIX700 and Alloy706

It seems that freckles are not classified clearly on the basis of the phenomenon. Though the mechanism of freckle formation is not fully revealed, it may be possible to compare the freckling tendency in large ingots. The H-DS experiment would be suitable for examining the 
freckling tendency. The H-DS experiment revealed which alloy should be selected for large products just from the freckle formation point of view.

\section{Summary}

Vertical solidification (V-DS) and horizontal solidification (H-DS) experiments were carried out to evaluate segregation test methods for freckles formed in large ingots.

1) Freckles were found on the surface of both upward and downward grown V-DS ingots.

2) All V-DS ingots showed more solute concentration in the case of downward growth directional solidification.

3) The chemical distribution in a V-DS ingot could be explained by a thermal convection induced rinse-off effect ahead of the solidification front.

4) Density inversion theory cannot explain surface freckles on V-DS Ni-base superalloy ingots.

5) The V-DS experiment was shown to be unsuitable for investigation of the tendency of channel segregation in large ingots.

6) The H-DS experiment would be a suitable method for assessing freckling tendency for channel segregation.

\section{REFERENCES}

1. S. Kjaer, F. Klauke, R. Vanstone, A. Zeijseink, G. Weissinger, P. Kristensen, J. Meier, R. Blum, K. Weighardt: Powergen Europe 2001, Brussels, (2001).

2. R. Viswanathan, R. Purgert, S. Goodstine, J. Tanzosh, G. Stanko, J. P. Shingledecker, B. Vitalis: 5th Inter. Conf. on Adv. in Mater. Tech. for Fossil Power Plants, EPRI, (2007).

3. A. D. Helms, C. B. Adasczik, and L. A. Jackman: Superalloys 1996, (1996), 427-433.

4. A. F. Giamei and B. H. Kear: Metall. Trans., 1 (1970) 2185-2192.

5. S. M. Copley, A. F. Giamei, S. M. Johnson, and M. F. Hornbecker: Metall. Trans., 1 (1970) 2193-2204.

6. H. Yamada, T. Sakurai, and T. Takenouchi: Tetsu-to-Hagane, 75 (1989), 97-104.

7. H. Yamada, T. Sakurai, and T. Takenouchi: Tetsu-to-Hagane, 75 (1989), 105-112.

8. H. Ishida, K. Sakamoto, M. Nohara, H. Oki, and K. Ohsasa: Tetsu-to-Hagane, 95 (2009), 2632.

9. S. Imano, H, Doi, K. Kajikawa and T. Takahashi: Superalloys 718, 625, 706 and various derivatives, TMS, Warrendale PA, (2005), 77-86.

10. T. Ohno, A. Toji, T. Uehara, G. Bao, T. Sato, J. Sato, and S. Imano: 5th Int. Conf. of Adv. in Mater. Tech. for Fossil Power Plants (2007).

11. R. Yamamoto, Y. Kadoya, H. Kawai, R. Magoshi, T. Noda, S. Hamano, S. Ueta, and S. Isobe: Proc. 7th Liege Conf. (2002). 
12. K. Suzuki, T. Miyamoto: Tetsu-to-Hagane, 63, (1977), 53-62.

13. B. Sundman, B. Jansson and J.-O. Andersson, CALPHAD, 9 (1985) 153-190.

14. N. Saunders: Superalloys 1996, TMS, Warrendale PA, (1996), 101-110.

15. K. Kajikawa, H. Yamada, S. Imano, and H. Doi: COMP-ISIJ, 18(4), (2005), 1129.

16. K. Kajikawa, T. Sato, and H. Yamada: Proceedings of Liquid Metal Processing and Casting, Sep. 20-23, Santa Fe, NM, 2009, TMS.

17. R. H. Mathiesen and L. Arnberg: International Center for Diffraction Data 2006, (2006), 3746.

18. B.Chalmers: Principles of Solidifications, John Wiley \& Sons, Inc., New York, 1964.

19. N. Streat and F. Weinberg: Metall. Trans., 5 (1974) 2539-2548.

20. A. Noeppel, A. Ciobanas, X. D. Wang, K. Zaidat, N. Mangelinck, O. Budenkova, A. Weiss, G. Zimmermann, and Y. Fautrelle: Metall. Mater. Trans. B, 41B, (2010), 193-208.

21. N. Stanford, A. Djakovic, B. Shollock, M. Mclean, N. D’Souza, and P. Jennings: Superalloys 2004, (2004), 719-726.

22. T. Iida: J. Jpn. Weld. Soc., 62 (1993), 590-594.

23. K. Mukai, Z. Li, and L. Fang: Mater. Trans. JIM, 45, (2004), 2987-2993.

24. Z. Li, and K. C. Mills: Metall. Mater. Trans. B, 37B, (2006), 781-790.

25. D. J. Steinberg: Metall. Trans., 5, (1974), 1341-1343. 